\title{
Public knowledge and awareness of stroke among adult population in Taif city, Saudi Arabia
}

Adnan A. Mubaraki, MD, Adel S. Alqahtani, Medical intern, Abdullatif A. Almalki, Medical intern, Abmed H. Almalki, Medical intern, Hamdan M. Alamri, Medical intern, Mishaal K. Aburass, Medical intern, Zeyad H. Althumali, Medical Intern.

\begin{abstract}

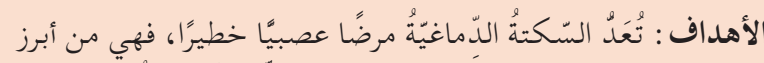

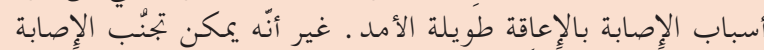

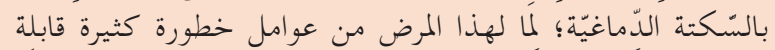

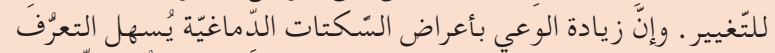

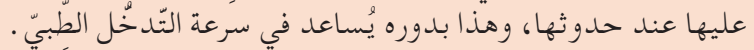
المنهجية : تَّ إجراء دراسة مقطعية على سكان مد ينة الطائف البالغين،

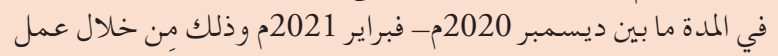
استبيان إلكترونيّ.

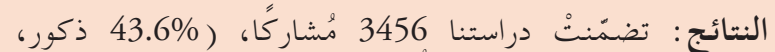

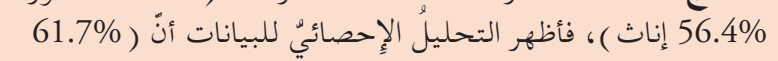

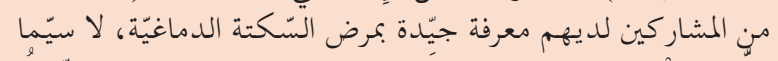

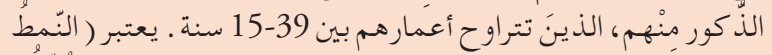

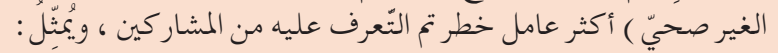

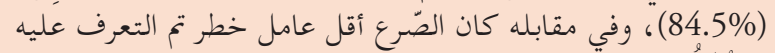

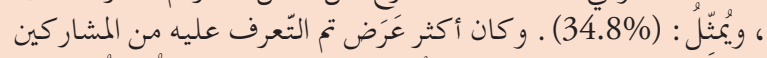

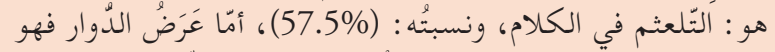

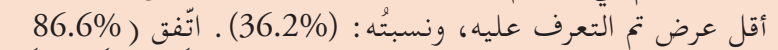

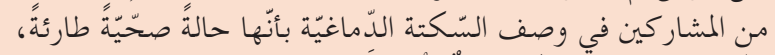

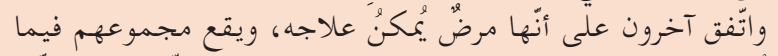

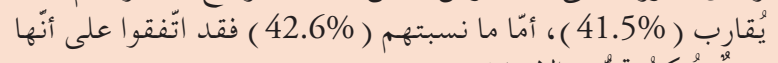

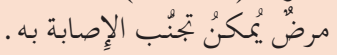

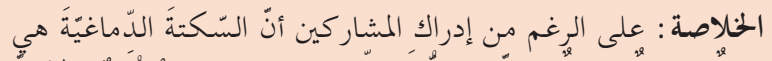

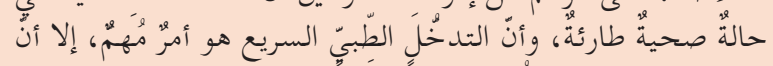

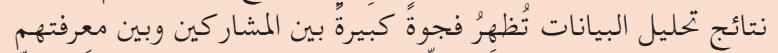

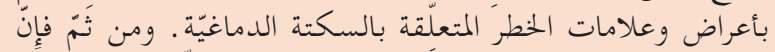

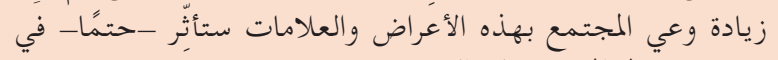
سرعة حصول المريض على العلاج.

Objectives: To evaluate the knowledge and awareness of stroke in adult population in Taif, Kingdom of Saudi Arabia and to address the association between several sociodemographic variables of participants and their knowledge regarding stroke.

Methods: A cross-sectional study was conducted among adult residents in Taif, Kingdom of Saudi Arabia, during the period of December, 2020 to February, 2021 using an online questionnaire.

Results: Our study included 3456 participants (43.6\% males, $56.4 \%$ females). Analysis showed that $61.7 \%$ of the participants were aware of stroke. Participants who were 15-39 years-old had good knowledge. Male participants had better knowledge than females. The most identified risk factor was 'unhealthy lifestyle' $(84.5 \%)$ and the least identified one was 'epilepsy' (34.8\%). The most identified symptom was 'slurred speech' (57.5\%), and the least identified one was 'dizziness' (36.2\%). Approximately 86.6\% of the participants agreed that stroke was a medical emergency. A total of $41.5 \%$ of the participants agreed that stroke was treatable and $42.6 \%$ agreed that stroke was a preventable disease.

Conclusion: Although the participants recognize that stroke is a medical emergency and that early intervention is crucial, the obtained results show that there is a large gap in the knowledge of the warning signs and symptoms of stroke. Increasing community awareness about these warnings may affect how quickly the patient is treated.

Neurosciences 2021; Vol. 26 (4): 339-345 doi: 10.17712/nsj.2021.4.20210057

From the Department of Medicine (Mubaraki), and from the College of Medicine (Alqahtani, Almalki A., Almalki H., Alamri, Aburass, Althumali), Taif University, Taif, Kingdom of Saudi Arabia.

Received 26th April 2021. Accepted 19th July 2021.

Address correspondence and reprint request to: Dr. Adel S. Alqahtani, College of Medicine, Taif University, Taif, Kingdom of Saudi Arabia. E-mail:Adel.alqa@gmail.com

ORCID ID: https://orcid.org/0000-0002-7634-4569 
Ctroke is a serious neurological disorder, and it is one $\checkmark$ of the major causes of long-term disability. ${ }^{1}$ Global prevalence of stroke is estimated to be 80 million cases in $2016 .^{2}$ Stroke can occur owing to ischemia or hemorrhage and causes damage of brain tissue leading to neurological function and cognitive deficits. ${ }^{3}$ Among different types of stroke, blockage of arterial supply in the brain, which is known as ischemic stroke, is the most common type of stroke. ${ }^{4}$ Stroke is a preventable neurological disease that has many modifiable risk factors. Patients with chronic diseases (namely, hypertension, diabetes mellitus, hyperlipidemia, and cardiac disease) or cigarette smokers (which are the commonest risk factors) are considered to have higher risk of stroke. ${ }^{5}$ Stroke risk increases in women using an oral contraceptive pills for long duration. ${ }^{6}$ Lifestyle modification (namely, salt restriction, smoking cessation, sports, and maintaining normal weight) can reduce the risk of stroke up to $50 \% .^{7}$ The incidence of stroke is decreasing in many countries due to improved high blood pressure control and decreased levels of smoking. ${ }^{8}$ Patients with risk factors should be aware of the risk of stroke and must have knowledge about the warning signs. Stroke warning signs include sudden numbness or weakness of the face or limbs, confusion, speaking difficulties, difficulty seeing, difficulty walking, and severe headache with an unknown cause. ${ }^{9}$ Early identification of stroke symptoms with early management of acute attack is very effective to reduce the burden of stroke complications. ${ }^{10}$ Lack of knowledge of the warning signs and the importance of time to manage stroke attack may lead to delay the decision of seeking medical help. ${ }^{11}$ Increasing stroke awareness expedites stroke symptom recognition and seeking medical attention. ${ }^{12}$

Stroke is the second leading cause of death worldwide (9.7\% of all deaths) just after ischemic heart disease. ${ }^{13}$ With aging, the incidence of stroke increases. The incidence reaches $670-970$ of 100,000 per year for people over 65 years old. ${ }^{14}$ The incidence of stroke in Kingdom of Saudi Arabia (KSA) is 29 per 100,000 people annually. ${ }^{15}$ It is a major cause of death and disability in KSA (with up to $6.4 \%$ mortality rate). ${ }^{16}$

Disclosure. Authors have no conflict of interests, and the work was not supported or funded by any drug company. This study was funded by Taif University Researchers supporting project (TURSP-2020/322), Taif University, Taif, Saudi Arabia
Methods. This is a descriptive cross-sectional study that was conducted during the period of December, 2020 to February, 2021 to assess general knowledge about stroke among adults in Taif, KSA. the purpose of the study was to evaluate the knowledge and awareness of stroke in adult population in Taif, KSA, and to address the association between several sociodemographic variables of participants and their knowledge regarding stroke. The study was performed on Taif residents. The ethical approval for our research was provided by the Deanship of scientific research, Taif university, Taif, KSA. as our research involved human subjects, the principles of Helsinki declaration were applicated.

Inclusion criteria were all male and female adults living in Taif, KSA, who were over 15 years old and agreed to participate in the study; all of them were invited to participate in the study on a voluntary basis and with an anonymous identity. They were allowed to withdraw at any time. All participants under 15 years old and those living outside Taif, KSA, were excluded.

Information from the participants who met the inclusion criteria and agreed to participate was obtained using a self-filling online questionnaire. The questionnaire was provided in English and Arabic and asked about sociodemographic variables of participants such as age, gender, education, and occupation. Questions about source of information and presence of different comorbidities were included, and the remaining questions assessed awareness, knowledge, risk factors, and warning signs.

The data was analyzed using the Statistical Package for Social Sciences version 23 (IBM Corp., Armonk, NY, USA) and presented as numbers and frequencies. To determine the relationship of categorical variables, Pearson's chi-square test was used.

Results. Our study was performed to assess the awareness of stroke and knowledge related to its risk factors, prevention, and treatment. Online survey responses from 3456 participants, who fulfilled the eligibility criteria and completely answered all items in the questionnaire, were included for analysis. Sociodemographic characteristics showed that $43.6 \%$ of the participants were males, and $56.4 \%$ were females. Other characteristics are shown in Table 1. The performed analysis showed that approximately $61.7 \%$ of the participants $(n=2134)$ were aware of stroke.

To calculate the level of knowledge related to stroke, the scores of all knowledge-related items in the questionnaire were added based on correct and incorrect responses. The correct answer for each item 
was given a score of one, and an incorrect answer was given a score of zero. Thus, the maximum knowledge score that one participant could get for the knowledge part related to stroke was 34, and the minimum score was zero. The mean total knowledge score for our study population was determined to be $16.8 \pm 7.2$. Based on the obtained percentages, the scores were categorized into good $(\geq 80 \%)$, fair $(60-79 \%)$, and poor $(<60)$. The obtained results showed that only $8.7 \%(n=300)$ of the participants had 'good' knowledge regarding stroke, and the majority $(69.7 \%)$ of the participants had 'poor' knowledge (Table 1).

When we assessed the relationship of knowledge with different age groups of the participants, it was determined that those who belonged to the 15-39 year-old age group demonstrated comparatively more 'good knowledge' than other age groups; this result showed a statistically significant relationship ( $p=0.002)$. Male participants had more 'good knowledge' (11.1\%) related to stroke and risk factors than females (6.8\%); this result showed a statistically significant correlation $(p<0.001)$. Participants who were single and had an education of bachelor or higher had comparatively more 'good knowledge', and those who had high school or lower education showed 'poor knowledge'; this result was significantly correlated $(p<0.001)$. Participants who were 'employed' and those who were students had comparatively more 'good knowledge' than those who were unemployed $(p<0.001)$. It was also determined that the knowledge was 'good' in participants who were smokers than those who never smoked; this result showed a statistically significant relationship $(p<0.05)$. Other variables (namely, nationality, income of the participants, and presence of chronic diseases) did

Table 1 - Relationship between knowledge and sociodemographic characteristics.

\begin{tabular}{|c|c|c|c|c|c|}
\hline \multirow[t]{2}{*}{ Characteristics } & \multirow[t]{2}{*}{ n (\%) } & \multicolumn{3}{|c|}{ Knowledge } & \multirow[t]{2}{*}{$P$-value $\left(\mathrm{X}^{2}\right)$} \\
\hline & & Good & $\begin{array}{l}\text { Fair } \\
\text { n (\%) }\end{array}$ & Poor & \\
\hline Total sample & $3456(100.0)$ & $300(8.7)$ & $746(21.6)$ & $2410(69.7)$ & \\
\hline \multicolumn{6}{|l|}{ Age } \\
\hline $\begin{array}{l}15-39 \\
40-59 \\
60 \text { or older }\end{array}$ & $\begin{array}{c}2477(71.7) \\
894(25.9) \\
85(2.5)\end{array}$ & $\begin{array}{c}241(9.7) \\
52(5.8) \\
7(8.2)\end{array}$ & $\begin{array}{c}520(21.0) \\
214(23.9) \\
12(14.1)\end{array}$ & $\begin{array}{c}1716(69.3) \\
628(70.2) \\
66(77.6)\end{array}$ & $0.002(17.367)$ \\
\hline \multicolumn{6}{|l|}{ Gender } \\
\hline $\begin{array}{l}\text { Male } \\
\text { Female }\end{array}$ & $\begin{array}{l}1508(43.6) \\
1948(56.4)\end{array}$ & $\begin{array}{l}167(11.1) \\
133(6.8)\end{array}$ & $\begin{array}{l}327(21.7) \\
419(21.5)\end{array}$ & $\begin{array}{l}1014(67.2) \\
1396(71.7)\end{array}$ & $<0.001(20.055)$ \\
\hline \multicolumn{6}{|l|}{ Marital status } \\
\hline $\begin{array}{l}\text { Married } \\
\text { Unmarried }\end{array}$ & $\begin{array}{l}1444(41.8) \\
2012(58.2)\end{array}$ & $\begin{array}{c}92(6.4) \\
208(10.3)\end{array}$ & $\begin{array}{l}325(22.5) \\
421(20.9)\end{array}$ & $\begin{array}{l}1027(71.1) \\
1383(68.7)\end{array}$ & $<0.001(16.899)$ \\
\hline \multicolumn{6}{|l|}{ Nationality } \\
\hline $\begin{array}{l}\text { Saudi } \\
\text { Not Saudi }\end{array}$ & $\begin{array}{l}3327(96.3) \\
129(3.7)\end{array}$ & $\begin{array}{l}288(8.7) \\
12(9.3)\end{array}$ & $\begin{array}{l}726(21.8) \\
20(15.5)\end{array}$ & $\begin{array}{l}2313(69.5) \\
97(75.2)\end{array}$ & $0.231(2.929)$ \\
\hline \multicolumn{6}{|l|}{ Education } \\
\hline $\begin{array}{l}\text { High school or lower } \\
\text { Bachelor or higher education }\end{array}$ & $\begin{array}{l}1063(30.8) \\
2393(69.2)\end{array}$ & $\begin{array}{c}53(5.0) \\
247(10.3)\end{array}$ & $\begin{array}{l}230(21.6) \\
516(21.6)\end{array}$ & $\begin{array}{l}780(73.4) \\
1630(68.1)\end{array}$ & $<0.001(27.066)$ \\
\hline \multicolumn{6}{|l|}{ Occupation } \\
\hline $\begin{array}{l}\text { Employed } \\
\text { Unemployed } \\
\text { Student }\end{array}$ & $\begin{array}{l}1053(30.5) \\
711(20.6) \\
1692(49.0)\end{array}$ & $\begin{array}{c}87(8.3) \\
32(4.5) \\
181(10.7)\end{array}$ & $\begin{array}{l}227(21.6) \\
148(20.8) \\
371(21.9)\end{array}$ & $\begin{array}{c}739(70.2) \\
531(74.7) \\
1140(67.4)\end{array}$ & $<0.001(26.615)$ \\
\hline \multicolumn{6}{|l|}{ Income } \\
\hline $\begin{array}{l}<5000 \\
5000-10000 \\
>10000\end{array}$ & $\begin{array}{l}1942(56.2) \\
604(17.5) \\
910(26.3)\end{array}$ & $\begin{array}{c}158(8.1) \\
51(8.4) \\
91(10.0)\end{array}$ & $\begin{array}{l}399(20.5) \\
132(21.9) \\
215(23.6)\end{array}$ & $\begin{array}{l}1385(71.3) \\
421(69.7) \\
604(66.4)\end{array}$ & $0.114(7.449)$ \\
\hline \multicolumn{6}{|l|}{ Smoking } \\
\hline $\begin{array}{l}\text { Absent } \\
\text { Present }\end{array}$ & $\begin{array}{l}2919(84.5) \\
537(15.5)\end{array}$ & $\begin{array}{l}236(8.1) \\
64(11.9)\end{array}$ & $\begin{array}{l}642(22.0) \\
104(19.4)\end{array}$ & $\begin{array}{c}2041(69.9) \\
369(68.7)\end{array}$ & $0.010(9.222)$ \\
\hline \multicolumn{6}{|l|}{ Chronic disease } \\
\hline $\begin{array}{l}\text { Absent } \\
\text { Present }\end{array}$ & $\begin{array}{l}2996(86.7) \\
460(13.3)\end{array}$ & $\begin{array}{l}259(8.6) \\
41(8.9)\end{array}$ & $\begin{array}{l}638(21.3) \\
108(23.5)\end{array}$ & $\begin{array}{l}2099(70.1) \\
311(67.6)\end{array}$ & $0.533(1.257)$ \\
\hline
\end{tabular}


not show any significant relationship with knowledge (Table 1).

The responses related to knowledge about different risk factors of stroke showed that the least identified risk factor by the participants was epilepsy (34.8\%), and the most identified one was 'unhealthy lifestyle' (84.5\%), followed by hypertension $(72.5 \%)$, and age $>65$ years (72.2\%; Table 2). When we assessed the knowledge related to symptoms of stroke, 'dizziness' was the least identified one by the participants (36.2\%), and the most identified one was 'slurred speech' (57.5\%; Table 2).
When the participants were asked about what would someone need to do if they saw a person who was having a stroke, it was agreed by $91.1 \%$ of the participants that they would immediately take the person to hospital or call emergency services (Table 3).

The performed analysis showed that approximately $13.3 \%(\mathrm{n}=460)$ of the participants had at least one more systemic disease that was a risk factor for stroke. Participants who had one or more systemic diseases had shown more 'good knowledge' related to stroke than those who did not have any systemic disease; however,

Table 2 - Knowledge related to different risk factors and symptoms of stroke by gender.

\begin{tabular}{|c|c|c|c|}
\hline Definition and cause, risk factors, and symptoms & Correct responses by gender & Total correct responses & $P$-value \\
\hline & $\mathrm{n}(\%)$ & & \\
\hline Stroke is a medical emergency & $\begin{array}{l}\text { M: } 1276(84.6) \\
\text { F: } 1717(88.1)\end{array}$ & $2993(86.6)$ & 0.003 \\
\hline Definition of stroke & $\begin{array}{l}\text { M: } 1230(81.6) \\
\text { F: } 1717(88.1)\end{array}$ & $2895(83.8)$ & 0.002 \\
\hline Type of strokes & $\begin{array}{l}\text { M: } 344(22.8) \\
\text { F: } 427(21.9)\end{array}$ & $2600(75.2)$ & 0.532 \\
\hline The most common type of stroke is ischemic stroke & $\begin{array}{l}\text { M: } 892(59.2) \\
\text { F: } 1212(62.2)\end{array}$ & $2104(60.9)$ & 0.067 \\
\hline Diabetes is a risk factor for stroke & $\begin{array}{l}\text { M: } 705(46.8) \\
\text { F: } 764(39.2)\end{array}$ & $1469(42.5)$ & $<0.001$ \\
\hline Hypertension is a risk factor for stroke & $\begin{array}{l}\text { M: } 1085(71.9) \\
\text { F: } 1420(72.9)\end{array}$ & $2505(72.5)$ & 0.537 \\
\hline Hyperlipidemia is a risk factor for stroke & $\begin{array}{l}\text { M: } 1028(68.2) \\
\text { F: } 1131(58.1)\end{array}$ & $2159(62.5)$ & $<0.001$ \\
\hline Epilepsy is a risk factor for stroke & $\begin{array}{l}\text { M: } 511(33.9) \\
\text { F: } 692(35.5)\end{array}$ & $1203(34.8)$ & 0.316 \\
\hline Heart disease is a risk factor for stroke & $\begin{array}{l}\text { M: } 829(55.0) \\
\text { F: } 1026(52.7)\end{array}$ & $1855(53.7)$ & 0.178 \\
\hline Family history for stroke consider a risk factor for stroke & $\begin{array}{l}\text { M: } 655(43.4) \\
\text { F: } 871(44.7)\end{array}$ & $1526(44.2)$ & 0.453 \\
\hline Incidence of stroke increase at age 65 years and older & $\begin{array}{l}\text { M: } 1085(71.9) \\
\text { F: } 1411(72.4)\end{array}$ & $2496(72.2)$ & 0.753 \\
\hline Unhealthy lifestyle increase the incidence of stroke & $\begin{array}{l}\text { M: } 1252(83.0) \\
\text { F: } 1667(85.6)\end{array}$ & $2919(84.5)$ & 0.040 \\
\hline Hemi-paralysis & $\begin{array}{l}\text { M: } 714(47.3) \\
\text { F: } 870(44.7)\end{array}$ & $1584(45.8)$ & 0.116 \\
\hline Weakness or numbness of one limb & $\begin{array}{l}\text { M: } 701(46.5) \\
\text { F: } 859(44.1)\end{array}$ & $1560(45.1)$ & 0.162 \\
\hline Weakness or numbness of the face & $\begin{array}{l}\text { M: } 587(38.9) \\
\text { F: } 741(38.0)\end{array}$ & $1328(38.4)$ & 0.595 \\
\hline Slurred speech & $\begin{array}{l}\text { M: } 844(56.0) \\
\text { F: } 1142(58.6)\end{array}$ & $1986(57.5)$ & 0.117 \\
\hline Severe headache & $\begin{array}{l}\text { M: } 621(41.2) \\
\text { F: } 865(44.4)\end{array}$ & $1486(43)$ & 0.058 \\
\hline Trouble seeing & $\begin{array}{l}\text { M: } 540(35.8) \\
\text { F: } 801(41.1)\end{array}$ & $1341(38.8)$ & 0.001 \\
\hline Imbalance & $\begin{array}{l}\text { M: } 680(45.1) \\
\text { F: } 1019(52.3)\end{array}$ & $1699(49.2)$ & $<0.001$ \\
\hline Confusion & $\begin{array}{l}\text { M: } 639(42.4) \\
\text { F: } 941(48.3)\end{array}$ & $1580(45.7)$ & 0.001 \\
\hline Dizziness & $\begin{array}{l}\text { M: } 520(34.5) \\
\text { F: } 731(37.5)\end{array}$ & $1251(36.2)$ & 0.065 \\
\hline
\end{tabular}


Table 3 - Knowledge related to prevention and treatment of stroke by gender.

\begin{tabular}{|c|c|c|c|}
\hline \multirow[t]{2}{*}{ Knowledge } & Responses by gender & Total responses & \multirow[t]{2}{*}{$P$-value } \\
\hline & \multicolumn{2}{|c|}{ Correct, $\mathbf{n}(\%)$} & \\
\hline Response when seeing a patient going through stroke & $\begin{array}{l}\text { M: } 1336(88.6) \\
\text { F: } 1814(93.1)\end{array}$ & $3150(91.1)$ & 0.033 \\
\hline Is there any current treatment for stroke? & $\begin{array}{l}\text { M: } 616(40.8) \\
\text { F: } 818(42.0)\end{array}$ & $1434(41.5)$ & 0.499 \\
\hline Early medical intervention will prevent severe disability following stroke & $\begin{array}{l}\text { M: } 1283(85.1) \\
\text { F: } 1744(89.5)\end{array}$ & $3027(87.6)$ & $<0.001$ \\
\hline A fully recovery from stroke is possible & $\begin{array}{l}\text { M: } 747(49.5) \\
\text { F: } 854(43.8)\end{array}$ & $1601(46.3)$ & 0.002 \\
\hline Is stroke a preventable disease? & $\begin{array}{l}\text { M: } 692(45.9) \\
\text { F: } 780(40.0)\end{array}$ & $1472(42.6)$ & 0.001 \\
\hline Stroke could be prevented by controlling blood pressure & $\begin{array}{c}\text { M: } 533(35.3) \\
\text { F: } 643(33.0)\end{array}$ & $1176(34)$ & 0.150 \\
\hline Stroke could be prevented by controlling blood sugar & $\begin{array}{l}\text { M: } 461(30.6) \\
\text { F: } 503(25.8)\end{array}$ & $964(27.9)$ & 0.002 \\
\hline Stroke could be prevented by controlling blood cholesterol & $\begin{array}{l}\text { M: } 510(33.8) \\
\text { F: } 561(28.8)\end{array}$ & 1071(31) & 0.001 \\
\hline Stroke could be prevented by quitting smoking & $\begin{array}{l}\text { M: } 520(34.5) \\
\text { F: } 584(30.0)\end{array}$ & $1104(31.9)$ & 0.005 \\
\hline Stroke could be prevented by doing regular exercise and eating healthy diet & $\begin{array}{l}\text { M: } 573(38.0) \\
\text { F: } 648(33.3)\end{array}$ & $1221(35.3)$ & 0.004 \\
\hline Stroke could be prevented by controlling using of blood thinner & $\begin{array}{c}\text { M: } 411(27.3) \\
\text { F: } 441(22.6)\end{array}$ & $852(24.7)$ & 0.002 \\
\hline
\end{tabular}

this result did not show any statistically significant relationship ( $p=0.533$; Table 1 ). Approximately $86.6 \%$ $(n=2993)$ of the participants agreed that stroke was a medical emergency, and $83.8 \% \quad(n=2895)$ of the participants mentioned that it occurred owing to lack of blood supply to the brain (Table 2). In our study, approximately $15.5 \%(\mathrm{n}=537)$ of the participants were smokers, and $15.1 \%(n=442)$ of those who agreed that smoking and unhealthy lifestyle practices increased the incidence of stroke were smokers $(p=0.282)$.

Upon assessing the knowledge among participants regarding the treatment of stroke, it was determined that $41.5 \%$ of the participants agreed that currently there was treatment available for stroke, and most of the participants believed that early medical intervention would prevent severe disability following the stroke. Only $46.3 \%$ of the participants believed that full recovery from stroke was possible, and $42.6 \%$ agreed that stroke was a preventable disease. The responses related to preventive measures for stroke were shown in (Table 3).

When we assessed the source of information related to stroke, $41.4 \%$ obtained it from TV or social media, $26.1 \%$ from friends and family, $22.2 \%$ from health workers, and $14.4 \%$ from books or flyers.

Discussion. Being more aware of stroke and its consequences will help with its early recognition and affect the prognosis through early medical intervention.

Our results showed that $69.7 \%$ of the participants had poor general knowledge about stroke. Mousa et $\mathrm{al},{ }^{16}$ showed that $76.6 \%$ of the participants had poor knowledge of stroke. Al-Beladi et al, ${ }^{17}$ showed that a large proportion of high-risk patients had poor awareness of the risk factors and warning signs of having a stroke. A study conducted in Qassim region, KSA, also showed a similar proportion of poor knowledge among hypertensive participants. ${ }^{18}$ Another study, which was performed to measure the knowledge of high school girls about stroke in the Eastern region of KSA, showed that most of the participants (91.1\%) had a low knowledge score. ${ }^{20}$ Poor knowledge level also was observed in Tabuk, KSA. ${ }^{19}$ Our research showed improved general knowledge about stroke compared to previous studies. This is likely due to the larger number of our participants were in the 15-39 age group. Which has more exposure to the recent advances in different technologies namely, internet which could have a synergistic effect in increasing awareness about different health problems. ${ }^{21}$ Also, may be due to curiosity of the younger generation to read and educate themselves about different health-related problems which was also found in a recent systematic review. ${ }^{22}$

A total of $83.8 \%$ of our participants correctly defined the cause of stroke as the lack of blood supply 
to the brain. Similar results were obtained from 2 other studies in KSA. ${ }^{16,20}$

Unhealthy lifestyle was the most identified risk factor for stroke followed by hypertension and old age. Diabetes and hypertension were the most identified risk factors in other studies. ${ }^{17,23}$ Epilepsy was the least identified risk factor for stroke; it was identified by only one-third of the participants, which was similar to a different study. ${ }^{16}$ New onset seizure at the old age should herald the suspicion of stroke. Epilepsy is yet to be determined as a risk factor for stroke. ${ }^{24}$

In our study, slurred speech was the most identified sign of stroke possibly because it could be quickly noticed by the participants. This was also reported in previous studies. ${ }^{23,25}$

Stroke is a medical emergency for which urgent medical intervention is needed; a total of $86.6 \%$ of the participants agreed with this statement. A similar result was obtained in multiple studies, which showed that a higher proportion of the responders would call an ambulance. ${ }^{16,26-28}$

A total of $20-30 \%$ of the participants from different studies believed that there was a treatment for stroke. ${ }^{16,17}$ This result should motivate the health care personnel and other health-related sectors to increase community awareness of the availability of specific stroke treatments, which may provide more time to the patients by bringing them early to emergency room (ER).

Rapid treatment and recovery from stroke attack often depend on the spouse or other family members. Continuous motivation and support provided by the family to the patient has significant impact on overall recovery from stroke. ${ }^{29}$ Lack of support and living alone have negatively affected the long-term prognosis after stroke. ${ }^{30}$ In addition, the male patient living alone after stroke attack were twice as likely to die as female patient living alone. ${ }^{31}$ Regular follow-up for clinics, rehabilitation centers and increasing self-esteem of the patient should be encouraged early after stroke.

In general, stroke can be prevented by controlling the risk factors. However, this was only known by $42.6 \%$ of the participants in our study. In the Western region, KSA, two-thirds of the participants agreed that lifestyle modification could help prevent stroke. ${ }^{16}$ Future studies are needed to address the effect of different methods of health education on controlling risk factors and how that will impact the stroke onset and recovery.

Limitations. Limiting the questionnaire to an online version which hindered the ability of illiterate people to participate is a limitation. The study was carried out in only one city is another limitation.

In conclusion, Taif adult population, KSA, has low level of knowledge regarding stroke. This is more noticeable in individuals who are older and have lower education level. Targeting this category can be carried out through campaigns on TV, street signs, and more visual measures to address the risk factors, symptoms, and the effect of early medical intervention on patients' prognosis by increasing the level of knowledge.

Acknowledgment. The authors would thank Taif University Researchers Supporting Project (TURSP-2020/322), Taif University, Taif, Saudi Arabia. The authors gratefully acknowledge Falcon Scientific Editing (https:/lfalconediting.com) for proofreading the English language in this paper.

\section{References}

1. Campbell BCV, De Silva DA, Macleod MR, Coutts SB, Schwamm LH, Davis SM, et al. Ischaemic stroke. Nat Rev Dis Primers 2019; 5: 70.

2. GBD 2016 Stroke Collaborators. Global, regional, and national burden of stroke, 1990-2016: a systematic analysis for the global burden of disease study 2016. Lancet Neurol 2019; 18 : 439-458.

3. Ma Y, Liu Y, Zhang Z, Yang GY. Significance of complement system in ischemic stroke: a comprehensive review. Aging Dis 2019; 10: 429-462.

4. MartInez-Coria H, Arrieta-Cruz I, Cruz ME, López-Valdés HE. Physiopathology of ischemic stroke and its modulation using memantine: evidence from preclinical stroke. Neural Regen Res 2021; 16: 433-439.

5. Boehme AK, Esenwa C, Elkind MS. Stroke risk factors, genetics, and prevention. Circ Res 2017; 120: 472-495.

6. Li F, Zhu L, Zhang J, He H, Qin Y, Cheng Y, et al. Oral contraceptive use and increased risk of stroke: a dose-response meta-analysis of observational studies. Front Neurol 2019; 10: 993.

7. Niewada M, Michel P. Lifestyle modification for stroke prevention: facts and fiction. Curr Opin Neurol 2016; 29: 9-13.

8. WHO EMRO. Stroke, cerebrovascular accident [Internet]. Geneva (CH): WHO; 2021. Available from: http://www.emro. who.int/health-topics/stroke-cerebrovascular-accident/index. html

9. American Stroke Association. know the warning signs of stroke [Internet]. USA: ASA; 2021. Available from: https://www. stroke.org/

10. Hurford R, Sekhar A, Hughes TAT, Muir KW. Diagnosis and management of acute ischaemic stroke. Pract Neurol 2020; 20: 304-316.

11. Vangen-Lønne AM, Wilsgaard T, Johnsen SH, Løchen ML, Njølstad I, Mathiesen EB. Declining incidence of ischemic stroke: what is the impact of changing risk factors? the tromsø study 1995 to 2012. Stroke 2017; 48: 544-550.

12. Ranawaka U, Mettananda C, Thilakarathna C, Peiris A, Kasturiratna A, Tilakaratna Y. Stroke awareness in patients with incident stroke compared to patients without stroke or ischemic heart disease. J Stroke Cerebrovasc Dis 2020; 29: 104790.

13. Jwarchan B, Yogi N, Adhikari S, Bhandari P, Lalchan S. A study of prevalence and predictors of acute ischemic CVA patients admitted to manipal teaching hospital, Pokhara, Nepal. Eastern Green Neurosurgery 2020; 2: 42-46. 
14. Benjamin EJ, Blaha MJ, Chiuve SE, Cushman M, Das SR, Deo $\mathrm{R}$, et al. Heart disease and stroke statistics-2017 update: a report from the american heart association. Circulation 2017; 135: e146-e603.

15. Alqahtani BA, Alenazi AM, Hoover JC, Alshehri MM, Alghamdi MS, Osailan AM, et al. Incidence of stroke among Saudi population: a systematic review and meta-analysis. Neurol Sci 2020; 41: 3099-3104.

16. Mousa O, Almujhem AA, Aljumaan RO, Alothman MA, Sayed A, Abstract. Public awareness of stroke among adult people in eastern region of saudi arabia, community-based cross-sectional study. Merit Research Journal of Medicine and Medical Sciences 2020; 8: 319.

17. Al-Beladi BA, Al-oufi KM, Alhazmi AM, Nafea RM, Ibrahim HM. Awareness of Stroke among Diabetic and Hypertensive Patients at King Fahad Hospital in Al-Madinah, KSA, 2016. Int JMed Res Prof 2018; 4: 172-176.

18. Mersal F, Tork H. Stroke risk perception and its awareness among hypertensive patients in Qassim region Saudi Arabia. Majmaah Journal of Health Sciences 2020; 8: 9.

19. Faisal atiah alzahrani, amjed eswed alenzy, abdulrahman mesfer alghamdi. stroke in tabuk, KSA: Awareness and prevalence of risk factors. life sci J 2019; 16: 38-42.

20. Alsubaie F, Alobaidallah F, Almustafa S, Alhazyim B, Ola Mousa AA. Assessing the knowledge of high school students about stroke as a leading cause of death in Saudi Arabia. South Asian Research Journal of Nursing and Healthcare 2020; 2: 17-22.

21. Miyamatsu N, Okamura T, Nakayama H, Toyoda K, Suzuki $\mathrm{K}$, Toyota A, et al. Public awareness of early symptoms of stroke and information sources about stroke among the general Japanese population: the acquisition of stroke knowledge study. Cerebrovasc Dis 2013; 35: 241-249.

22. Park E, Kwon M. Health-related internet use by children and adolescents: systematic review. J Med Internet Res 2018; 20: e120.
23. Alhazzani AA, Mahfouz AA, Abolyazid AY, Awadalla NJ, Ahmed RA, Siddiqui AF, et al. Awareness of stroke among patients attending primary healthcare services in Abha, Southwestern Saudi Arabia. Neurosciences (Riyadh) 2019; 24: 214-220.

24. Chang CS, Liao CH, Lin CC, Lane HY, Sung FC, Kao CH. Patients with epilepsy are at an increased risk of subsequent stroke: a population-based cohort study. Seizure 2014; 23: 377-381.

25. Alluqmani MM, Almshhen NR, Alotaibi RA, Aljardi OY, Zahid HM. Public awareness of ischemic stroke in Medina city, Kingdom of Saudi Arabia. Neurosciences (Riyadh) 2021; 26: 134-140.

26. Krishnamurthi RV, Barker-Collo S, Barber PA, Tippett LJ, Dalrymple-Alford JC, Tunnage B, et al. Community knowledge and awareness of stroke in New Zealand. J Stroke Cerebrovasc Dis 2020; 29: 104589.

27. Alqwaifly M, alghasham G, alkadi SA, aloyaidi GA. Awareness of stroke risk factors, warning symptoms, and significance of acute management and prevention in Qassim, Saudi Arabia. IJMDC 2020; 4: 2158-2163.

28. Krzystanek E, Krzak-Kubica A, Świat M, Galus W, Gawryluk J. Adequate knowledge of stroke symptoms, risk factors, and necessary actions in the general population of Southern Poland. Brain Sci 2020; 10: 1009.

29. Stiexs A, Chayati N. Study of physical, psychological, and spiritual impact of family caregiver in home-based stroke treatment: a systematic review. Open access Macedonian journal of medical sciences 2021; 9: 236-239.

30. Ishikawa Y, Hifumi T, Urashima M. Influence of living alone or with a spouse only on the short-term prognosis in patients after an acute ischemic stroke. Int J Environ Res Public Health 2020; 17: 8223 .

31. Redfors P, Isaksén D, Lappas G, Blomstrand C, Rosengren A, Jood $\mathrm{K}$, et al. Living alone predicts mortality in patients with ischemic stroke before 70 years of age: a long-term prospective follow-up study. BMC Neurol 2016; 16: 80.

\section{Clinical Practice Guidelines}

Clinical Practice Guidelines must include a short abstract. There should be an Introduction section addressing the objective in producing the guideline, what the guideline is about and who will benefit from the guideline. It should describe the population, conditions, health care setting and clinical management/diagnostic test. Authors should adequately describe the methods used to collect and analyze evidence, recommendations and validation. If it is adapted, authors should include the source, how, and why it is adapted? The guidelines should include not more than 50 references, 2-4 illustrations/tables, and an algorithm. 